\title{
Research on Power Coal Supplier Selection Based on AHP and Fuzzy Comprehensive Evaluation Method
}

\author{
Shaomei Yang Rui Wang \\ Department of Economics and Management, \\ North China Electric Power University \\ Baoding, China, 071000 \\ yangshaomei77@126.com wangruifish@163.com
}

\begin{abstract}
In the circumstance of supply chain management, the coal suppliers, as the upper reaches of the power coal supply chain, have a direct influence to thermal power enterprises. Therefore, it is extremely important to determine suitable power coal suppliers effectively. Firstly, this paper, according to the characteristics of the power coal supplier, established the indicator system based on three aspects. Then this paper proposes the AHP method to determine the electricity supplier evaluation index weight distribution, and using the fuzzy comprehensive method to evaluate and choose the power coal suppliers. Finally, an example is shown to explain the evaluation method and a conclusion is given.
\end{abstract}

Keywords: AHP; Power coal; Supplier selection;

Fuzzy comprehensive evaluation method

\section{Introduction}

Electric power industry is the basis of national economy in our country. It is a foundation of basic demand for human daily life, and the key point to guarantee a continuously high speed growing economy. Thermal power generation is the main factor. And the Electricity-coal is main power of thermal power enterprises. But our coal resources are distributed nonuniformly. The majority coal resource is in undeveloped areas such as Shanxi, Shanxi, west Inner Mongolia. The problem is that South-east China where there is large consumption of electricity is in lack of coal resources. This reverse distribution between coal source and needing area caused the transportation between northwest to southeast and north to south. Besides, the government does not control coal price now, but still limit electricity price strictly. The market-based coal price and planned electricity price are making price games between thermal power industry and coal industry. When there is tension of coal supply, coal price rises but coal quality drops. This increased thermal power enterprises' running cost and also affect safety production directly.

In supply chain management mode, the competitions between single enterprises become the competitions between the supply chains ${ }^{[1]}$. Choosing correct partners is important to improve whole competitiveness of whole supply chain. Therefore, choosing electricity-coal suppliers is very important to thermal power enterprise under tense electricity-coal supply situation. This determines whether electricity enterprises can provide enough power and also affects electricity enterprises' survival and development. This article establishes relatively well-developed assessment indicator system, applies AHP method to ensure index weight and uses fuzzy synthetic evaluation method to establish decision matrix, in order to fulfill comprehensive assessment for electricity-coal suppliers choice.

\section{AHP -Fuzzy Comprehensive Evaluation Method Principle}

\subsection{AHP}

AHP (Analytic Hierarchy Process) was initially brought forward in the 1970s by the famous American operations research expert T. L. Saaty. The basic thought of the AHP is that: identify the factors from the problem and then divide into different hierarchies corresponding to different evaluation levels, experts evaluate relative importance of each factor in a lower hierarchy relative to the corresponding factor in an upper hierarchy and form judgement matrix, and gain the relative importance of every factor by calculating ${ }^{[2]}$.The specific steps are as follows:

(1) Construct analytic hierarchy model 
Hierarchy usually includes target layer, criteria layer and Scheme level. The target layer at the top of the model is the goal which decision-makers are to achieve eventually. Criteria layer in the middle layer is the criterion of decision-making. Scheme layer at the bottom, includes the specific means to solve the problem.

(2) Construct the judgment matrix

Judgement matrix is the relatively important matrix among the various factors of the present hierarchy that are relevant to a certain factor of the last hierarchy. The relative importance of the degree can be indicated by the scales 1 to 9, the judgment matrix Scale and its meaning are shown in Table 1.

Table 1 Judgment matrix scales and its meaning

\begin{tabular}{|c|l|}
\hline Mark & Meanings \\
\hline 1 & One factor is equal to another \\
\hline 3 & One factor is more important than another trivially \\
\hline 5 & One factor is more important than another obviously \\
\hline 7 & $\begin{array}{l}\text { One factor is more important than another } \\
\text { intensively }\end{array}$ \\
\hline 9 & One factor is more important than another extremely \\
\hline $2,4,6$, & Middle grades between higher mark and lower mark \\
8
\end{tabular}

(3) Test the consistency of the judgment matrix

We need to test the consistency of the judgment matrix in order to assess whether the weights is reasonable.

We use the random consistency ratio $C R$ to test the consistency of judgment matrix, $\mathrm{CR}=\mathrm{CI} / \mathrm{RI}$,among them, $\mathrm{CI}$ is the ordinary consistency ratio of judgement matrix, $\mathrm{CI}=\left(\lambda_{\max }-\mathrm{n}\right) /(\mathrm{n}-1)$. RI is the average random consistency index. The value of average random consistency index is shown in Table 2. When C.R. $<0.10$, the judgement matrix has satisfactory consistency.; when C.R. $\geq 0.10$, the judgement matrix needs to be adjusted until it is satisfied.

Table 2 Table of average random consistency index

\begin{tabular}{|c|c|c|c|c|c|}
\hline $\mathrm{n}$ & 1 & 2 & 3 & 4 & 5 \\
\hline $\mathrm{RI}$ & 0.00 & 0.00 & 0.58 & 0.90 & 1.12 \\
\hline $\mathrm{n}$ & 6 & 7 & 8 & 9 & 10 \\
\hline $\mathrm{RI}$ & 1.14 & 1.32 & 1.41 & 1.45 & 1.49 \\
\hline
\end{tabular}

(4) The total level of sorting and Countermeasures

In the single-sorted based on the total ranking of different levels of the system to calculate the weight of finally obtained the influence of different factors on the target level, according to the weight coefficients related personnel to take the appropriate strategy size.

\subsection{Fuzzy Comprehensive Evaluation Method}

In 1965, the cybernetics expert Zade from California University published an important article named "fuzzy sets", which declared the birth of fuzzy mathematics. The main steps are as follows.

(1) Establishing the fuzzy comprehensive evaluation index and evaluation ranks

Establishing factors set of fuzzy object $U=\left\{\mathrm{u}_{1}\right.$, $\left.\mathrm{u}_{2}, \ldots, \mathrm{u}_{\mathrm{m}}\right\}$.Here, $\mathrm{u}_{\mathrm{i}}(\mathrm{i}=1,2, \ldots, \mathrm{m})$ is evaluation factors, $\mathrm{m}$ stands for number of single factor of the same hierarchy. Establishing evaluation set of fuzzy object. $\mathrm{V}=\left\{\mathrm{v}_{1}, \mathrm{v}_{2}, \ldots \mathrm{v}_{\mathrm{n}}\right\}$. Here, vi $(\mathrm{i}=1,2, \ldots, \mathrm{n})$ is evaluation grades standard. The $\mathrm{n}$ stands for the number of elements also refers to evaluation grades. The set gives a selecting scope of evaluation result of a factor ${ }^{[3]}$.

(2) Building indicators system and establish index system weight.

There are many approaches to achieve index weight, Such as Analytic Hierarchy Process, Entropy weight method, Main component analysis method and so on. The paper adopts Analytic Hierarchy Process to evaluate index weight.

(3) Single factor fuzzy evaluation

A single factor evaluation for the number of $\mathrm{i}$ evaluation factor is carried out and a fuzzy vector to $v_{j}$ is acquired. $\mathrm{Ri}=\left(\mathrm{r}_{\mathrm{i} 1}, \mathrm{r}_{\mathrm{i} 2}, \ldots, \mathrm{r}_{\mathrm{ij}}\right), \mathrm{i}=1,2,3, \ldots, \mathrm{m} ; \mathrm{j}=1,2$, $3, \ldots, n$. The $r_{i j}$ is the degree which the factor $u_{i}$ attributes to $\mathrm{v}_{\mathrm{j}}, 0<\mathrm{r}_{\mathrm{ij}}<1$. If we carry out a comprehensive evaluation for $\mathrm{n}$ elements, the result is an $\mathrm{m} * \mathrm{n}$ matrix. The matrix is called membership degree.

$R=\left(r_{i j}\right)_{m \times n}=\left(\begin{array}{cccc}r_{11} & r_{12} & \cdots & r_{1 n} \\ r_{21} & r_{22} & \cdots & r_{2 n} \\ \vdots & \vdots & \cdots & \vdots \\ r_{m 1} & r_{m 2} & \cdots & r_{m n}\end{array}\right)$

(4) Fuzzy comprehensive evaluations

Index weight $\mathrm{W}$ and membership degree matrix $\mathrm{R}$ are established, then fuzzy arithmetic operators are established. Finally, the paper carries out fuzzy compound calculation. 


$$
B=A \circ R=\left(a_{1}, a_{2}, a_{3} \cdots, a_{n}\right) \circ\left(\begin{array}{cccc}
r_{11} & r_{12} & \cdots & r_{1 n} \\
r_{21} & r_{22} & \cdots & r_{2 n} \\
\vdots & \vdots & \cdots & \vdots \\
r_{m 1} & r_{m 2} & \cdots & r_{m n}
\end{array}\right)
$$

$$
=\left(b_{1}, b_{2}, \cdots b_{n}\right)
$$

\section{Coal Supplier Evaluation Index System}

Choosing supplier under Supply Chain Management, is not looking for the supplier that have lowest cost or the shortest delivery time, but choosing the supplier that possess highly specialized technology core competence and long-term, fewer but better, sufficient spirit of cooperation, mutual reciprocity and mutual benefit ${ }^{[4]}$. Thermal coal supplier evaluation index is varied, and sometimes even contradictory. So in order to guarantee the scientificalness and rationality of evaluation, generally follow the following principles to set up the supplier evaluation index system ${ }^{[5]}$.(1) the principle of combining comprehensive and general; (2) the principle of combining qualitative and quantitative; (3) the principle of combining the scientificalness and operability; (4)the principle of expandability.

According to the basic principles above, this article from three aspects: the strategic factors, products, services, selecting and evaluating the supplier, and establishes a basic evaluation framework of relationship orientation between the thermal power enterprise and coal supplier . Strategic factors include enterprise scale, enterprise prestige and the enterprise management level, product factors include product quality, product price, on time delivery and product flexibility, service factors include service attitude, service response and the technical service level. Thermal coal supplier evaluation index system has been shown in figure 1 .

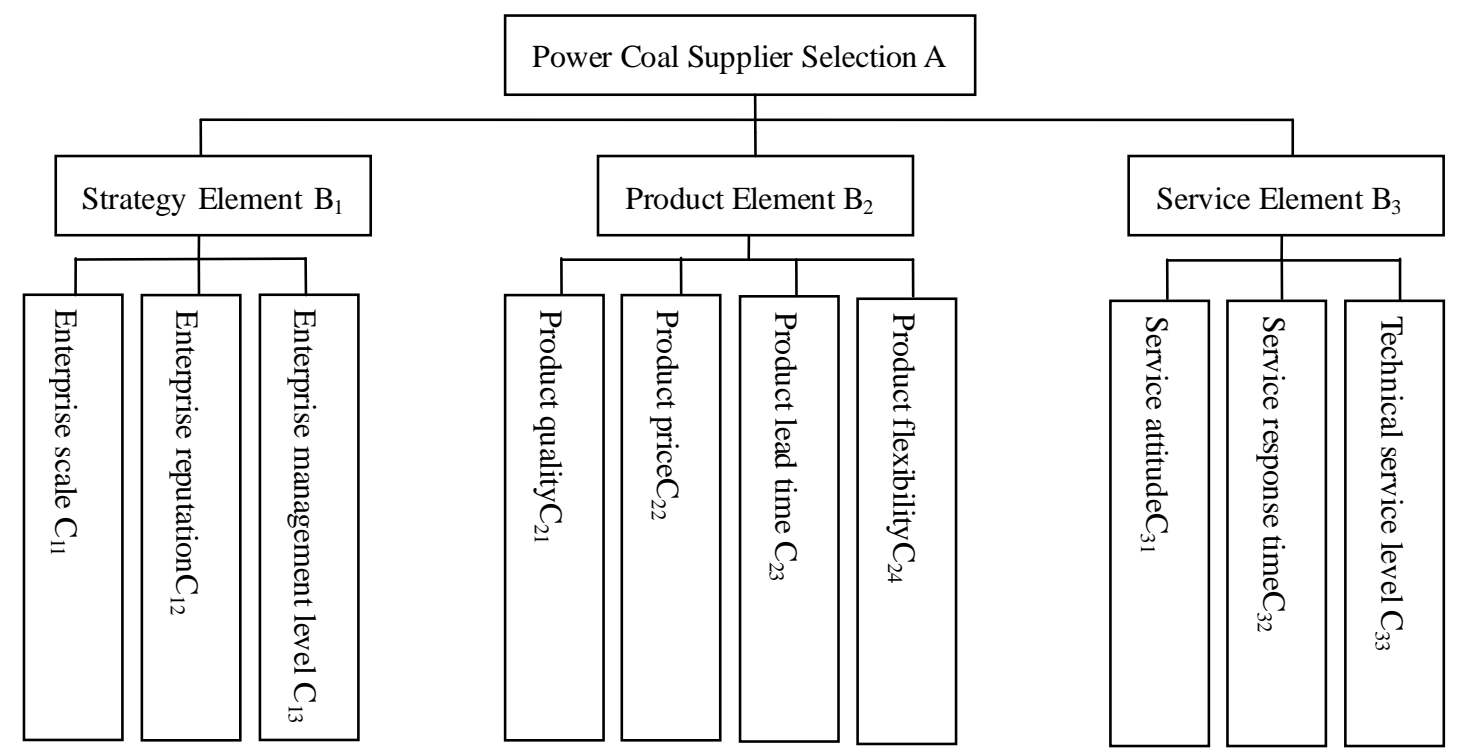

Fig. 1 Thermal coal supplier evaluation index system

\section{Empirical Studies}

Taking a thermal power enterprise as an example, there are four candidate coal suppliers: A, B, C, D. The thermal power enterprises need to choose one of the four suppliers as its long-term and stable cooperation partner. According to the statistical data and expert judgment, the judgment matrix is constructed as follow in Table 3-6. And at the same time, using programming soft MATLAB, the maximum characteristic value and the weights can also be found as follows:
Table 3 judgment matrix A-B

\begin{tabular}{|c|c|c|c|c|}
\hline $\mathrm{A}$ & $\mathrm{B}_{1}$ & $\mathrm{~B}_{2}$ & $\mathrm{~B}_{3}$ & weight \\
\hline $\mathrm{B}_{1}$ & 1 & 1 & 2 & 0.4000 \\
\hline $\mathrm{B}_{2}$ & 1 & 1 & 2 & 0.4000 \\
\hline $\mathrm{B}_{3}$ & $1 / 2$ & $1 / 2$ & 1 & 0.2000 \\
\hline
\end{tabular}

Note: $\lambda_{\max }=3, \mathrm{CI}=0, \mathrm{CR}=0<0.10$

Table 4 Judgement matrix B1-C

\begin{tabular}{|c|c|c|c|c|}
\hline $\mathrm{B}_{1}$ & $\mathrm{C}_{11}$ & $\mathrm{C}_{12}$ & $\mathrm{C}_{13}$ & weight \\
\hline $\mathrm{C}_{11}$ & 1 & $1 / 2$ & $1 / 2$ & 0.1980 \\
\hline $\mathrm{C}_{12}$ & 2 & 1 & 2 & 0.4900 \\
\hline $\mathrm{C}_{13}$ & 2 & $1 / 2$ & 1 & 0.3120 \\
\hline
\end{tabular}

Note: $\lambda_{\max }=3.0536, \mathrm{CI}=0.0268, \mathrm{CR}=0.0516<0.10$ 
Table 5 Judgement matrix B2-C

\begin{tabular}{|c|c|c|c|c|c|}
\hline $\mathrm{B}_{2}$ & $\mathrm{C}_{21}$ & $\mathrm{C}_{22}$ & $\mathrm{C}_{23}$ & $\mathrm{C}_{24}$ & weight \\
\hline $\mathrm{C}_{21}$ & 1 & 1 & 3 & 4 & 0.4013 \\
\hline $\mathrm{C}_{22}$ & 1 & 1 & 3 & 3 & 0.3375 \\
\hline $\mathrm{C}_{23}$ & $1 / 3$ & $1 / 2$ & 1 & 2 & 0.1638 \\
\hline $\mathrm{C}_{24}$ & $1 / 4$ & $1 / 3$ & $1 / 2$ & 1 & 0.0974 \\
\hline
\end{tabular}

Note: $\lambda_{\max }=4.0310, \mathrm{CI}=0.0103, \mathrm{CR}=0.0116<0.10$

Table 6 Judgement matrix B3-C

\begin{tabular}{|c|c|c|c|c|}
\hline $\mathrm{B}_{3}$ & $\mathrm{C}_{31}$ & $\mathrm{C}_{32}$ & $\mathrm{C}_{33}$ & weight \\
\hline $\mathrm{C}_{31}$ & 1 & 2 & 5 & 0.5815 \\
\hline $\mathrm{C}_{32}$ & $1 / 2$ & 1 & 3 & 0.3090 \\
\hline $\mathrm{C}_{33}$ & $1 / 5$ & $1 / 3$ & 1 & 0.1095 \\
\hline
\end{tabular}

Note: $\lambda_{\max }=3.0037, \quad \mathrm{CI}=0.0018, \quad \mathrm{CR}=0.0036<0.10$

The decision set $\mathrm{V}=\{\mathrm{A}, \mathrm{B}, \mathrm{C}, \mathrm{D}\}$ represents the four different candidate coal suppliers. Expert evaluation data after processing have been shown in table 7 .

Table 7 Fuzzy comprehensive evaluation

\begin{tabular}{|c|c|c|c|c|}
\hline factors & A & B & C & D \\
\hline Enterprise scale & 0.85 & 0.83 & 0.87 & 0.95 \\
\hline Enterprise reputation & 0.83 & 0.72 & 0.80 & 0.90 \\
\hline Enterprise management level & 0.80 & 0.78 & 0.74 & 0.87 \\
\hline Product quality & 0.74 & 0.76 & 0.82 & 0.83 \\
\hline Product price & 0.87 & 0.72 & 0.93 & 0.88 \\
\hline Product lead time & 0.83 & 0.83 & 0.90 & 0.87 \\
\hline Product flexibility & 0.77 & 0.92 & 0.87 & 0.83 \\
\hline Service attitude & 0.82 & 0.68 & 0.87 & 0.91 \\
\hline Service response time & 0.84 & 0.82 & 0.91 & 0.87 \\
\hline Technical service level & 0.90 & 0.91 & 0.87 & 0.89 \\
\hline
\end{tabular}

(1) Hierarchical comprehensive evaluation

$$
B_{1}=A_{1} \circ R_{1}=(0.1980,0.4900,0.3120) \circ\left(\begin{array}{cccc}
0.85 & 0.83 & 0.87 & 0.95 \\
0.83 & 0.72 & 0.80 & 0.90 \\
0.80 & 0.78 & 0.74 & 0.87
\end{array}\right)
$$$$
=(0.8246,0.7605,0.7952,0.9005)
$$

$B_{2}=A_{2} \circ R_{2}=(0.4013,0.3375,0.1638,0.0974) \circ\left(\begin{array}{cccc}0.74 & 0.76 & 0.82 & 0.83 \\ 0.87 & 0.72 & 0.93 & 0.88 \\ 0.83 & 0.83 & 0.90 & 0.87 \\ 0.77 & 0.92 & 0.87 & 0.83\end{array}\right)$

$=(0.8015,0.7736,0.8751,0.8534)$
$B_{3}=A_{3} \circ R_{3}=(0.5815,0.3090,0.1095) \circ\left(\begin{array}{cccc}0.82 & 0.68 & 0.87 & 0.91 \\ 0.84 & 0.82 & 0.91 & 0.87 \\ 0.90 & 0.91 & 0.87 & 0.89\end{array}\right)$

$=(0.8349,0.7484,0.8824,0.8955)$

(2) High level comprehensive evaluation

$B=A \circ R=(0.4000,0.4000,0.2000) \circ\left(\begin{array}{llll}0.8246 & 0.7605 & 0.7952 & 0.9005 \\ 0.8015 & 0.7736 & 0.8751 & 0.8534 \\ 0.8349 & 0.7484 & 0.8824 & 0.8955\end{array}\right)$

$=(0.8174,0.7633,0.8446,0.8807)$

(6)

Based on the results: the order of the four candidate coal suppliers is: D, C, A, B. Therefore, the coal supplier D is the best choice.

\section{Conclusions}

The effective choice of coal supplier is related to the Stable and sustainable development of the thermal power enterprise. This paper proposes a model which combines both AHP and fuzzy comprehensive evaluation method to evaluate and select the suitable coal supplier, at last through the practical example the method is proved to be reasonable and Scientific in the application of the coal supplier evaluation and selection.

\section{Acknowledgements}

Supported by "the Fundamental Research Funds for the Central Universities" (12MS134)

\section{References}

[1] Guan Shimin. Under the environment of supply chain supplier selection method and its application [D]. Liaoning: Northeastern University of business administration, 2006.

[2] Du Dong etc. Modern comprehensive evaluation method and case selection (second edition) [M]. Beijing: Tsinghua University press, 2008.

[3] Wang Hongli and Zhou shugong, A study of performance evaluation of ERP system implementation on AHP-FUZZY comprehensive evaluation theory, Proceedings of the Ninth International Conference on Machine Learning and Cybernetics, Qingdao, 11-14 July 2010.

[4] Liu Jiacai and Zhao Wenjian. Research on Supplier selection based on fuzzy comprehensive evaluation method [J]. logistics management, 2012, (45) : 13-14.

[5] Tian Bo and Yang Aifeng. Improved fuzzy comprehensive evaluation model in the application of supplier selection [J]. Logistics Technologies, 2007 (8): 66-69. 